\title{
The transport of dangerous goods on infrastructure in The Netherlands
}

\author{
S. I. Suddle \\ Delft University of Technology \& SSCM BV, The Netherlands
}

\begin{abstract}
Institutions shape a policy field and therefore also actors' behavior. The Dutch policy field of 'External Safety' is used to assure a basic level of safety for people living near transport routes of hazardous materials or other hazardous activities. When it comes to transport of hazardous materials and the risks for adjacent areas, a number of problems arise. This paper discusses the need for an alternative institutional framework which can serve as a solution for the problems found. A possible first step is to get rid of a general risk norm as a policy goal and to use a more project specific approach as an alternative. This approach should be combined with a test for the reasonability of lowering risks based on the ALARP principle.
\end{abstract}

Keywords: transport of dangerous goods, risk analysis, external safety.

\section{Introduction}

A shortage of land across The Netherlands has led to the development of design and construction techniques that enables intensive use of the limited space. In the last decade, the space available adjacent to and above the transport infrastructure has been used at a growing rate in city centres. In addition, line infrastructure for transport of hazardous materials is mostly also in use for passenger transport and therefore often crosses densely populated urban areas. The new development strategies of the Dutch Ministry of Housing, Spatial Planning and Environment regarding space in urban areas pay special attention to these issues. However, the Dutch spatial planning policy, which aims to intensify the use of space [1], may come into conflict with the intentions set out in the Fourth National Environmental Policy Plan, which states that additional (open) space is sometimes necessary to guarantee external safety [2]. 
In The Netherlands, regulations for land-use planning in the vicinity of major industrial hazards are explicitly risk-based. This implies that potential adverse physical effects of incident scenarios are considered along with their probability of occurrence and their possible impacts. One of the main reasons for implementing the risk policy is a shortage of space, as a result of which the optimal space according to the effect distance of a worst case scenario between a risk generating activity and urban development cannot be achieved. Three main elements constitute the Dutch regulatory risk framework. These elements are: (i) quantitative risk assessment, (ii) the adoption of individual and group risk as risk-determining parameters and (iii) acceptability criteria for individual and group risk. Basically, risk consists of three components: the scenario, the probability of this scenario and the consequence of the scenario [3]. Risk is described in the Dutch policy practice as the formula: the probability of an accident multiplied by its effect. This is therefore the most frequently used definition in Dutch risk analysis.

In order to reduce the risks concerning the transport of hazardous materials on infrastructure within the boundaries of the risk criteria, technical measures are generally taken. For example, if the risk exceeds the norm on a certain location, measures taken are for example the decreasing the maximum speed, removing track-changes from a certain part of the railway tracks or preventing the dispersion of hazardous substances [4]. These technical measures then reduce the risk of transport with respect to urban planning, due to the fact that either the probability variable or the effect variable (or, of course, both) are lowered. In practice, however, still problems occur with this more technical approach as the norms that are set for this so-called External Safety Policy are exceeded in several cases (see for example [2, 5]).

In the following sections, we will unfold the first steps towards a possible new way of managing risks in The Netherlands by matter of philosophizing on risks and deducting possibilities for a new or different institutional framework. The purpose of this article is to show what might happen if new ideas on risk management and risk analysis are implemented into the decision-making on external safety. For this to occur, we will start by looking briefly at the role of institutions in a policy field and what this means for the present risk management framework in The Netherlands (section two). Section three will illustrate a number of objections to the present framework. In section four we will contemplate on whether it is possible to create a new institutional framework. In the fifth section, we will demonstrate our view on risk management and institutions and discuss the consequences and disadvantages. In the final section, we will discuss our findings and conclusions.

\section{Safety and risk management of third parties}

\subsection{Risk assessment}

In the Dutch practice there are two acceptance criteria. The first one is called Individual Risk (IR). This is the probability that an unprotected person dies due 
to an accident with hazardous materials per year on a certain spot when this person resides here a full year. The individual risk depends on the geographical position and is displayed by means of risk contours on a geographical map. The individual risk is thus not characteristic for any person, but only for the location for which it is calculated. Thus, the individual risk contour maps give information on the risk of a location, regardless of whether people are present at that location or not (see Figure 1). The maximum allowed risk as laid down in Dutch law, is $1 \times 10^{-6}$. This means that an additional involuntary risk which is lower than once every million years is found acceptable according to Dutch policy. The second risk indicator generally applied in The Netherlands is Group Risk (GR). GR is defined as the probability per year that in an accident more than a certain number of people are killed. Group risk is usually represented as a graph in which the cumulative frequency of more than $n$ fatalities is given as a function of $N$, the number of people killed. This graph is called the fN curve (see Figure 2).

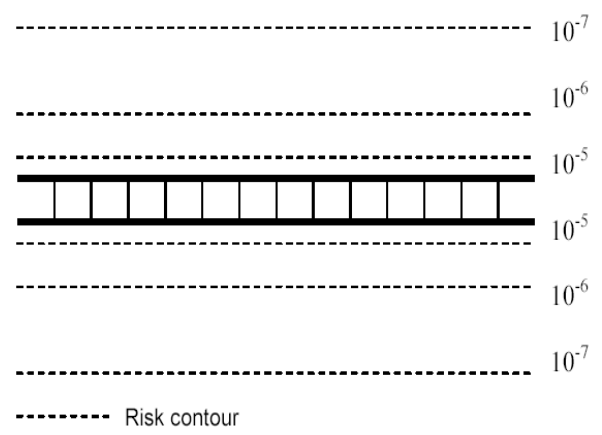

Figure 1: Schematic visualization of individual risk near a railroad.

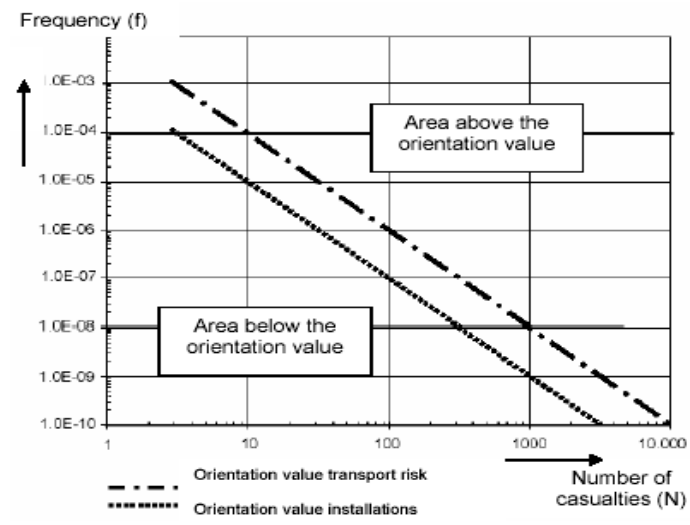

Figure 2: Schematic reproduction of an exceeding of the group risk criterion. 
In the Dutch risk policy, the risk acceptance standards for the IR are included in binding rules. Therefore, vulnerable objects cannot be built within the $10^{-6}$ contour. However, the GR is rather an indication criterion with a so-called orientation value as decision standard. Figure 2 shows two diagonal curves which represent the orientation value for GR installations (below) and transportation risk. When a calculated GR exceeds the orientation value, the acceptance of the GR must be motivated by local authorities. Economic aspects and repressive measures are widely considered in such a motivation. So, the orientation value is not binding by law and acts more as a guideline for policy makers and planners to review their plans including safety aspects. Moreover, the decision-makers - mostly the local municipality - can weigh the risk (qualitatively) with e.g. economic or environmental aspects. It should be noticed that the decision-makers are juridical responsible for accepting the exceeded risk. In practice, the GR orientation values are generally taken into account when deciding upon new projects or large urban adjustments in a consisting project with relation to urban planning adjacent to or above infrastructure with hazardous materials transport [6].

\subsection{Risk estimation and risk analysis}

In the Dutch practice, transport risks of hazardous materials are estimated with several mathematical Quantitative Risk Assessment (QRA) models, resulting in a presentation of the so-called risk picture. The primary QRA model used in The Netherlands is the so-called RBMII model [7]. This standardized model is free of use and distributed by the Dutch Ministry of Transport, Public Works and Water Management. This is done to satisfy a need for a relatively simplified, standardized and validated method to calculate relevant risk values [8]. This model is assumed to be the benchmark model for all risk analyses to be made regarding transport of hazardous materials, except for highly complex nonstandard situations, such as risk calculations in case of a building realized above the infrastructure [7, 9]. The RBMII model uses many more assumptions in its calculations than just probability and effect, but it basically boils down to the standard formula of risk of Kaplan and Garrick [3]. The model considers input parameters such as accident frequencies, the speed of the train on the considered rail track, the amount of level crossings, the amount of track switches et cetera. The effect of a possible derailment is calculated by such variables as the amount and the type of hazardous materials released, resulting in physical effects on people, which depends on the amount and duration of people living in the adjacent area and the distance between the center of the track and the built up area.

The calculations made for the IR and the GR are based on all possible scenarios. These scenarios are based on imaginary incidents with different types of transported hazardous materials. The effect of the transport of category $\mathrm{C} 3$ materials (flammable liquids) is dominant for the IR contours. Sometimes the effects of toxic liquids or flammable gasses are dominating (AVIV \& Saxxion, 2005). Since the influence of the C 3 category is dominant for IR-contours, the $10^{-6}$ contour appears to be hardly more than 30 meters from the centre of the 
railway track. The theory behind this is that a leaking tank generally cannot create a pool (fire) with a diameter of more than 30 meters. Moreover, a minimum amount of more than 3000 tanks per year is needed to create a $10^{-6}$ contour outside the railway track. For the calculation of the GR, the worst case scenario is a BLEVE (Boiling Liquid Expanding Vapor Explosion). A BLEVE is the consequence of the failure of a pressure vessel containing a liquefied, mostly flammable, gas. The quick change of the liquid phase to the vapor phase goes hand in hand with a big volume increase, causing the explosion-effect. In the most cases, the evaporated gas is ignited, resulting in a fireball with an effect diameter of possibly more than 300 meters causing large number of fatalities [10]. This scenario influences the GR value by more than $90 \%$.

\subsection{Safety management and risk control}

Unfortunately a number of locations (40 to 50 spots) where current risk acceptance criteria for the group risk are already exceeded [5], such as nodes for the transport of hazardous materials, are also the locations for which the Fifth National Policy Document on Spatial Planning of The Netherlands desires intensification, combination and transformation. One could say that in these cases risks are not as low as they should be according to Dutch policy. To summarize the preceding, in the node estimation of risks, frequency and the potential consequences in numbers of fatalities along with possible scenarios is analyzed with software, e.g. RBMII. The node Risk analysis provides the calculated and quantified risks for the considered area in which the potentially vulnerable vicinity, including people along with the risk generating activity (transport of hazardous materials) are located. During risk assessment process, the calculated risks are evaluated with the risk acceptance criteria. In case of exceeding the norm, it can be considered if the exceeded risk is acceptable and whether risk reduction is necessary. However, there is still a large number of locations where risks are exceeded.

\section{Objections to these institutions}

From a command and control perspective, Dutch policy standards which relate to environmental issues are a common good. De Roo [11] points out that the Dutch government has set out strict quantitative standards for human activities in favor of protecting the environment for more than thirty years. When the policy is made, norms affect regional and local authorities by means of generic norms which sets limits for other types of policy relating to the living environment. These norms include such environmental areas as to prevent air pollution, noise or to control soil pollution.

A calculated norm however, could provoke objections regarding the method of calculating risks. Several reports $[12,13]$ object to these calculations since they consider it as a technocratic rational way of risk management and design of risk policy. In their opinion this way of managing risks is either a strategy designed to supply a technical rational basis for a centralized regulatory decision making 
[12] or a scientific weakness to provide an instrumental, calculative and purposive rationality [13].

In the terms of quantitative risk analysis, $[12,13]$ object to the rational view on how to manage risks. This means that, in their opinion, risk is more than just a number based on which one can decide on whether something is acceptable or not. To come to a better understanding of risks Healy [13] concludes that a more substantive dialogue between the natural and social sciences needs to be achieved. Fischer [12] adds that it is also necessary to provide a framework for a more participatory approach due to which lay-men can also speak out to risks. In addition, he notes that there is a lack of coordination between the technical and the social aspects of risk. This means there should be coordination between the quantified risk and the subjective side of the story, which is the opinion of the public on the question of what is acceptable.

Linnerooth [14] argues that despite the increasing role of public institutions in the regulation of technological risks, the developing literature on risk assessment has had virtually no rooting in understanding organizational behavior or political progress. According to her, the rational decision-making model as a prescriptive tool, has been usefully applied to decisions at the level of the individual or firm, but is misleading and inappropriate when transplanted to the public arena, where decisions are not 'made' by a single individual, but are negotiated, not comprehensively, but sequentially, by competing groups and institutions.

Notions on the matter of acceptable risk is the notion that problems which stem from this matter are basically problems in decision making, which therefore require a choice amongst alternatives [15]. In addition, this choice depends on the set of options, consequences, values and facts invoked in the decisionmaking process. This means there cannot be a single panacea, or all-purpose number that expresses the acceptable risk for a society. Or: 'At best, one can hope to find the most acceptable alternative in a specific problem. Indeed, 'acceptable risk' may be a poor term if it connotes universality' [15].

Moreover, Van der Vlies [16] argues that rail transport risks are not the same type of risks that are associated with the big sociological and technological hazards that are associated with such authors as Beck, Giddens and Perrow. However, it is not said that risk norms could not help decision makers to estimate the expected physical harm as they (could) provide the best available knowledge about actual damage that is logically or empirically linked with each possibility of action (see e.g. [17]). Furthermore, it should be noted that the calculation of an $\mathrm{fN}$-curve is just an estimation, rather than an exact presentation of risk results [18]. In addition to that, the presented models and results are simplified depictions of reality and should be in fact used to measure the effect on both human and economical risks regarding safety measures [9].

These arguments make it clear that the present institutional framework is suboptimal. This still leaves a question unanswered, because what would be a better way to deal with risks? Suppose the norms for external safety would not exist; what would happen then? On which base will decisions be made? Can this improve safety or is the system good as it is? The next section will first explore conditions that limit the possible solutions. 


\section{Some limiting conditions}

It is possible to create new ideas on how to reduce the probability of an accident, and also the risk of a disaster, by creating design concepts that are the safest. However, such design concepts are both structurally and financially almost impossible to realize, because the theoretical dimensions of such measures are enormous. For that reason, the investments in concepts are extremely high and could even be higher than a single project budget [9]. Therefore, prohibiting transport of hazardous materials or prohibiting urban development are both controversial and almost impossible solutions. From this point of view, there is a strong need for design concepts that stimulate the continuity of both the transport of hazardous material and the urban development above or adjacent to those transport routes, if possible. Ideas such as tunneling all transport or a nation wide ban on the transport of hazardous materials are therefore not taken into account in this article. Also, even though external safety policy is a Dutch policy, there are fixed European institutions that have their influence on the Dutch external safety as well.

Another limiting condition is caused by the European directive on the free transport of goods [19]. When transporting goods on the national level, quantitative limits can be set by the national government. The ideas for the basic network for example consist of such ideas. As a consequence, transporters may consider their own transport modality and may thus not be hindered in their operational management. This may result in differing transport flows of hazardous materials on transport routes. When comparing the transport numbers of 2003 and 2004 in The Netherlands, for example, the transport of flammable gasses shows an increase between $90 \%$ and $100 \%$ [21,22], resulting in an increase of the dominant group risk scenario with 90 to $100 \%$ as well. As the transport itself, in principle, is not to be influenced in a free market society, we will neither challenge nor discuss the amount of transported materials.

Finally, it is necessary to accept the created present risk situations adjacent to railroads, particularly in areas where the orientation value of the GR is exceeded. At some moment in time, there apparently was consensus on the created physical situation. We therefore accept this situation as given and do not debate this.

When we accept these three limiting factors, we can elaborate on new institutional principles for risk management and external safety. This is done through deduction of possibilities through conditional reasoning. Conditional reasoning is based on an 'if $\mathrm{A}$ then $\mathrm{B}$ ' construct that posits $\mathrm{B}$ to be true if $\mathrm{A}$ is true. If we take into account the objections to a quantitative approach to risk analysis and management and the fact that the GR criterion is not met in a large number of places, it might be a solution to use another way of dealing with risks in terms of acceptability. In the present situation, risks are acceptable when they do not exceed the orientation value in the $\mathrm{fN}$ curve.

When compared to the quite similar British situation for example, The Netherlands have a different interpretation in the acceptance of risk and what the term reasonability implies. Apparently, the Dutch interpretation is that reaching the norm also limits the discussion, whereas in the United Kingdom the limits 
have the aim of realizing ALARP [22]. The ALARP approach shows an upper limit of risk that can be tolerated in any circumstances and a lower limit below which risk is of no practical interest [23]. It is, however, also associated with quantitative levels of risk, which, are used as an illustration only. This means that the quantified numbers of transport of hazardous materials are taken as a starting point, instead of an end point. According to [22], however, the difference between the Dutch 'Roman law' and British 'common law' legislative systems implies that it is very difficult to implement such a criterion. The question to answer in the next section therefore is: can the ALARP criterion be put into Dutch practice and how can it be used as a potential risk reducing policy tool?

\section{First steps towards a new institutional framework}

Suppose that we would use the ALARP criterion; how should this be implemented and how would this influence risk management? If one talks about reasonability, this is often expressed in terms of costs and benefits. Bowles [24] for example, talks about a disproportionality ratio, which, in his words, is a Cost/ Benefit ratio that includes both economic and life safety benefits. The advantages of this approach are:

- An improved assurance that all reasonably foreseeable failure modes have been identified and adequately addressed.

- A stronger safety case for the risk reduction decision.

- A stronger business case for the risk reduction decision.

- A greater degree of defensibility for the risk reduction decision (Bowles, 2003).

With respect to reducing risks as low as reasonably practical, Bowles [24] has made a good effort to create a formula which expresses what reasonable costs are. In both articles, in which he calculates reasonability of costs to prevent dam failure, he presents the 'Disproportionality Ratio', $\mathrm{R}$. $\mathrm{R}$ is equal to:

\section{[Annualized Cost of Risk Reduction Measure- Annualized Economic Benefit of Risk Reduction Measure] \\ divided by \\ [Annualized Life Safety Benefit of Risk Reduction Measure]}

As the equation is not directly applicable to transport, we will not get in too much detail how the calculation is made. It suffices, for now, to say that the calculation is a more sophisticated description of a standard cost / benefit analysis.

Suppose, however, that a disproportionality ratio could also be applied to transport of hazardous materials, what might the consequences be? A way to explain this is to visualize this with the $\mathrm{fN}$ curve. Measures can be taken at the frequency variable (f) or the effect variable $(\mathrm{N})$. Frequency is in that case is a derivative of the probability variable from the risk formula. Effect on the other hand is only expressed in terms of the number of fatalities in a certain area. 
Figures 3(a) and (b) give a schematic reproduction what this means in terms of the Group Risk criterion.

Figure 3(b) implies that if the ALARP method is applied the norm for GR can still be exceeded. However, the measure taken (I) of (II) also imply that the overall risk is much smaller than in the previous situation as presented in figure 3(a). It is remarkable that in a number of cases the risk in the present situation exceeds the norm with a factor of up to 90 times [5], there is no possibility that the norm will be reached, unless measures are taken that can cost more than the entire project. Hence, one may criticize the stringiness of the GR criterion.

The RBMII model, in our opinion can still function really well in relation to ALARP, but with a different basic assumption. It is therefore not necessary to get rid of the quantitative risk analysis tools or software. Instead of functioning as a more or less binding analytical tool it could function more as a decision supportive tool. Hereby, it is also possible to show in which project risks could be ALARP.

It should also be noted that applying the ALARP criterion, in principle, might reduce risks in present situations where the norm is not exceeded. In our view, using the ALARP criterion can continuously improve safety and reduce risks, which is also a policy goal for the Dutch Ministry of Transport, Public Works and Water Management [7]. The possible, and also likely, implication of this idea is that by implementing ALARP, the present Dutch External Safety norms will not be met in all cases. When taking the preceding into account, it should be possible to combine all the previous notions into a new framework for decisionmaking on urban planning projects in relation to transport of hazardous materials on infrastructure.
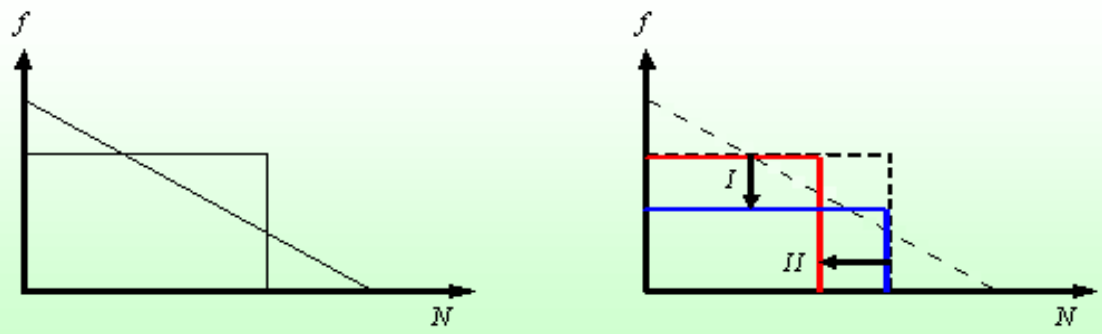

Figure 3: $\quad$ (a) A schematic reproduction of an exceeding of the Group risk criterion without the ALARP principle. (b) A schematic reproduction of an exceeding of the Group Risk criterion with different possible calculated outcomes due to the ALARP principle.

\section{6 (Dis)advantages}

The main advantages of such a framework could be the following. First of all, the implementation of a model for ALARP means that for the first time, a 
consideration can be made between safety aspects, transport and urban development. This leads to a situation in which the reasonability of an investment can be calculated through a cost-benefit analysis. Furthermore, a different use of the RBMII model becomes possible. As a consequence, this means that risks are calculated for individual cases. Each case then shows a certain level of risk in a new situation (i.e. a situation in which a newly developed urban project is planned) which can be compared to the old situation. Therefore, instead of calculating maximum levels of risk levels, risks are calculated to show the increase or decrease of risk in a specific situation. If a risk needs to be lowered to the level of the old situation, the ALARP model should be able to show whether this is possible to reasonable costs. This can be done by calculating the costs and benefits of different alternatives to lower risks. For the local authorities who want to develop their urban areas, this model is a good way to give account of their plans to lower risks to their citizens. Also this framework should lead to a new impulse to lower risks in places where the risks are too high. Finally, this method should serve as an interim period until a real solution is found by building new dedicated freight railroads that do not run through dense urban areas.

The main disadvantage of this approach is that the basic level of safety, which, at present, should be guaranteed by the use of risk norms, will be lifted. But one can ask whether this is a real problem as there are so many places where the risks are too high.

\section{Conclusions and discussion}

This article deals with risks surrounding the transport of hazardous materials and possible new institutions to control and to lower risks. Apparently, the present set of institutions is insufficient when it comes to controlling risks to acceptable levels. However, the meaning of such terms as acceptability, reasonability and practicality are, up to now, unclear.

In this article, we have intended to make a first initiative for a new way of looking at risks. This is done by discussing the possible positive consequences of using a formula to express ALARP. This article shows that a hypothetical change in Dutch external safety policy could evolve to a different set of institutions. Due to the fact that there is not one way of dealing with transport risks, there are also several ways these risks can be dealt with. Therefore, this is just $a$ way and not the way a different institutional framework could look like.

Furthermore, risk problems are decision problems that require a choice among alternatives [25]. What is an acceptable or tolerable risk depends on the decision maker and how he or she deals with uncertainties and what is deemed acceptable. Besides this, they say that there are no universally acceptable options, risks, costs or benefits as they depend on the set of options, consequences, values and facts examined in the decision-making process [25]. This means that there is no single criterion or solution for problems involving risks. When RBMII and a formula for ALARP are combined, this closely links to 
what [25] argues, because this model does not limit solutions to a single standard or solution.

There are of course a number of objections or comments that can be made with our way of looking at risks. First of all, there are a number of uncertainties. The presented ideas do not give definitive answers to questions surrounding whether they will also happen in practice. Secondly, there is no empirical research done (yet) to these matters. At this moment we agree that this article would be of more value when we could present such a model for ALARP in combination with empirical research. This, unfortunately, has not been possible yet. However, in order to come to other ways of managing risks and to explore alternatives in how to deal with risks that exceed the norm; the presented ideas are useful options for further exploration. In additional research, the authors hope to make a contribution and to test whether the statements made can be verified through empirical research.

\section{References}

[1] Ministerie van VROM (2001): Ruimte maken, ruimte delen: Vijfde Nota over de Ruimtelijke Ordening 2000/2020, Ministerie van VROM, Den Haag, 300 pp.

[2] Raad voor de Verkeer en Waterstaat \& Vromraad (2003): 'Verantwoorde risico's, veilige ruimte'. Den Haag.

[3] Kaplan, S. \& B.J. Garrick (1981): On the quantitative definition of risk, Risk Analysis, Volume 1, pp. 11 - 27.

[4] Wiersma, T., M. Molag \& J.W. Ekelenkamp, Toetsing Externe Veiligheid Spoorzone Dordrecht / Zwijndrecht, TNO rapport TNO-MEP-R2004/105, Apeldoorn, The Netherlands, 2004, 26 pp.

[5] AVIV \& Royal Haskoning (2005): Consequentie onderzoek externe veiligheid transport gevaarlijke stoffen.

[6] Van der Heijden \& Van der Vlies (2005): 'Spanning tussen stedelijke ontwikkeling en externe veiligheid: de casus Arnhem-centraal'. Tijdschrift voor Veiligheid en Veiligheidszorg. Jaargang 4, nummer 3.

[7] Ministerie van Verkeer en Waterstaat (2006a): 'Nota vervoer gevaarlijke stoffen'. Den Haag.

[8] Ministerie van Verkeer en Waterstaat (2006b): 'Wat is RBMII?'. Retrieved January 14, 2006.

[9] Suddle, S.I. (2004), Physical Safety in Multiple land use, Ph.D. Dissertation, Delft University of Technology, Delft. Also downloadable from URL: http://repository.tudelft.nl/file/354674/203416.

[10] Berg, A.C. van den \& J. Weerheijm, 2004: 'Uptun: Explosion effects in Traffic Tunnels', TNO Report, PML 2004, Rijswijk, 42 pp.

[11] De Roo, G. (2003): 'Environmental planning in the Netherlands: Too Good to be true. From command-and-control planning to shared governance'. Ashgate, Hampshire.

[12] Fischer, F. (2003): Risk assessment and environmental crisis: Toward an integration of science and participation. In: Campbell, S. \& S.S. Fainstein 
(eds.) Readings in Planning theory. Blackwell Publishing Ltd., Malden, MA, USA.

[13] Healy, S. (2001): Risk as social process: the end of 'the age of appealing to the facts?' In: Journal of Hazardous Materials, 86, pp.39-53.

[14] Linnerooth, J. (1984): Political processing of uncertainty. In: Acta Psychologica. Volume 56, pp. 219-231.

[15] Slovic, P., B. Fischhoff, S. Lichtenstein (1984): 'Behavioral decision theory perspectives on risk and safety'. In: Acta psychological. Volume 56, pp. 183-203.

[16] Van der Vlies, A.V. (2007): 'Towards a new perspective on rail transport of hazardous materials and its risks'. Conference paper presented at AESOP 2007 on 11-15 July, Napoli, Italy.

[17] Renn, O. (1998): The role of risk perception for risk management. In: Reliability engineering and system safety. Volume 59, pp. 49-62.

[18] Bedford, T., Cooke, R.M.(2001): Probabilistic Risk Analysis: Foundations and methods; Cambridge University Press.

[19] VNG (2004): 'VNG-visie op externe veiligheid'. Oktober 2004.

[20] Prorail (2005): 'Spoortransport gevaarlijke stoffen 2003: brandbaar gas (A)'. Capaciteitsmanagement, oktober 2005.

[21] Prorail (2006): 'Spoortransport gevaarlijke stoffen 2004: brandbaar gas (A)'. Capaciteitsmanagement, maart 2006.

[22] Ale, B.J.M. (2005): Tolerable or acceptable: A comparison of risk regulation in the United Kingdom and in the Netherlands. In: Risk Analysis. Vol. 25, No. 2, pp. 231-241.

[23] Melchers, R.E. (2001): 'On the ALARP approach to risk management'. In: Reliability Engineering and system safety. Volume 71, pp. 201-208.

[24] Bowles, D.S. (2003). 'ALARP Evaluation: Using cost effectiveness and disproportionality to justify risk reduction'. Presented at the ANCOLD 2003 conference on dams.

[25] Fischhoff, B., S. Lichtenstein, P. Slovic, S.L. Derby, R.L. Keeney (1981). 'Acceptable risk'. Cambridge University Press. 